\title{
Salvage surgery for head and neck squamous cell carcinoma
}

\author{
Magis Mandapathil • Marion Roessler • \\ Jochen A. Werner $\cdot$ Carl E. Silver · Alessandra Rinaldo • \\ Alfio Ferlito
}

Received: 24 February 2014 / Accepted: 31 March 2014 / Published online: 23 April 2014

(C) Springer-Verlag Berlin Heidelberg 2014

\section{Introduction}

Head and neck squamous cell carcinoma (HNSCC) is the sixth most common cancer worldwide and fifth most frequent cause of malignancy-related mortality [1,2]. Despite advances in various treatment modalities, the overall prognosis of HNSCC patients has not improved significantly within the last several decades. About $50 \%$ of patients survive their disease [3]. Advanced tumors have a recurrence rate of around $20-30 \%$ at the primary tumor site and 10 $15 \%$ in the neck [3].

Throughout most of the twentieth century, resectable advanced-stage HNSCC was treated by radical surgical approaches and primary radiochemotherapy (pRCT) was reserved for the treatment of locally advanced, unresectable tumors. However, over the past two decades, non-surgical organ-preservation strategies such as primary radiotherapy (pRT) or pRCT have been increasingly applied as treatment

This paper was written by members and invitees of the International Head and Neck Scientific Group (http://www.IHNSG.com).

M. Mandapathil · J. A. Werner

Department of Otolaryngology, Head and Neck Surgery, Philipp

University, Marburg, Germany

M. Roessler

Department of Pathology, Philipp University, Marburg, Germany

C. E. Silver

Departments of Surgery and Otolaryngology, Head and Neck Surgery, Montefiore Medical Center, Albert Einstein College of Medicine, Bronx, NY, USA

\section{A. Rinaldo $\cdot$ A. Ferlito $(\square)$}

University of Udine School of Medicine, Piazzale S. Maria della

Misericordia, 33100 Udine, Italy

e-mail: a.ferlito@uniud.it modalities for resectable stage III and IV cancers as an alternative to surgical management. This development has led to an increasing role for salvage surgery in cases of recurrent disease. In HNSCC, salvage surgery is, besides aggressive re-irradiation if applicable, often the only curative option in patients with locoregional recurrence [4].

Among patients with advanced HNSCC treated with definitive $\mathrm{pR}(\mathrm{C}) \mathrm{T}$ or adjuvant $\mathrm{R}(\mathrm{C}) \mathrm{T}$, locoregional recurrence develops in $18-20 \%$ of cases and in $17-33 \%$ of patients treated with definitive RCT for locally advanced, unresectable tumors [5]. Locally, recurrent tumors may arise from residual neoplastic cells that survive initial treatment-most likely due to biological factors that provide radio- and/or chemoresistance, the existence of cancer stem cells, or insufficiencies in initial treatment parameters such as radiation dose, volume, fractionation and/or treatment duration. Also, secondary tumors following $\mathrm{pR}(\mathrm{C}) \mathrm{T}$ may develop from underlying field cancerization, as a radiationinduced malignancy, or as a de novo process.

For patients with resectable disease recurrence, salvage surgery is considered the standard of care and may provide long-term disease control in up to $45 \%$ of patients with advanced and up to $80 \%$ of patients with early recurrent disease $[3,6]$. However, recurrence rates after salvage surgery, even when negative margins have been obtained, are high [7]. The rate of recurrence following salvage surgery has been described as $54.9 \%$ in a retrospective analysis of patients with oropharyngeal cancer and cancer of the oral cavity, with an overall five-year survival rate of $32.3 \%$. In this study, significant prognostic factors in multivariate analysis were recurrent tumor stage $(p=0.049)$ and disease-free interval ( $p=0.045)$ [8]. Röösli et al. [9] showed in a retrospective study of 156 patients with recurrent oropharyngeal tumors that five-year overall survival and disease-specific survival after salvage treatment was 29 and 
$40 \%$. With reference to specific initial treatment modalities, after initial pRT, survivals were 25 and $40 \%$; after initial surgery followed by radiation therapy, 40 and $40 \%$; and after initial surgery alone, 20 and $40 \%$. The authors concluded that despite poor ultimate outcome, salvage treatment should be attempted in patients with resectable disease, good performance status and absence of distant metastases.

The term salvage surgery is not clearly defined and has been used variously to describe a second attempt at cure after definite treatment or the final attempt for cure in case of recurrent disease following previous surgery, previous RT or RCT or a combination of the options mentioned. In HNSCC, salvage surgery is often the only curative option available and is mainly performed as the final curative attempt. The term salvage surgery is currently also used incorrectly for elective surgery following initial treatment and for persistent disease following an initial treatment attempt [10].

In this editorial, we review current applications of salvage surgery in HNSCC patients with a focus on indications for its rational use in different settings.

\section{Challenges in salvage surgery}

The tissue toxicity resulting from previous irradiation and chemotherapy produces a higher incidence of complications after salvage surgery than after initial surgery performed on healthy tissue. Acute toxicity is an inflammatory response leading to impaired wound healing and increased risk of infections. Late toxicity, fibrosis and avascularity, also impairs wound healing and repair. Complications of salvage surgery are often multiple and interrelated, including infection, bleeding and formation of pharyngocutaneous fistula (PCF) resulting in complex and prolonged wound healing phases, and often require additional interventions $[11,12]$. The frequency of complications is correlated with the clinical stage of the recurrent tumor: $>20 \%$ in stage I and II tumors, $>30 \%$ in stage III tumors and $>35 \%$ in stage IV tumors [13]. Complication rates as high as $40-53 \%$ have been reported in the literature [14]. The key to successful salvage is appropriate patient selection with adequate preoperative measures including correction of co-morbidities, cessation of smoking and alcohol, improvement of nutritional deficits and eradication of methicillin-resistant Staphylococcus aureus (MRSA) infection $[12,15,16]$.

Specific aspects contributing to complications in salvage surgery include advanced medical co-morbidities, comorbidities related to prior treatment for HNSCC and prior tracheostomy, age and tumor location outside the larynx [12]. Recurrent tumors of the oropharynx, hypopharynx and larynx are diagnosed in more advanced disease stages compared with primary tumors [17]. Therefore, a wellexperienced surgical team must conduct salvage surgery. An interdisciplinary approach to minimize complications and improve survival and functional outcome is required.

\section{Preventive measures}

Patients suspected of recurrent disease should undergo a restaging evaluation prior to a decision on salvage surgery. In addition to evaluation for locoregional disease, distant metastases have to be ruled out as recurrent disease is associated with the existence of distant metastases [18]. The most important diagnostic procedure and standard to screen for distant metastases in HNSCC is a CT scan of the thorax to evaluate for pulmonal and mediastinal lesions [19]. Some authors suggest the use of positron emission tomography to increase sensitivity in screening for distant metastasis [19-21]. However, this technique has not become a routine practice in many centers yet, as clear data on its predominance over conventional methods are pending and its use is cost-intensive and access often limited. The patient's co-morbidities and life expectancy, performance status, speech and swallowing function, nutritional status and severity of current symptoms need to be evaluated and documented. The patient needs to be educated about the often complex surgery with extensive reconstructive procedures.

Preoperative measures may be undertaken for correction of co-morbidities, nutritional deficiencies and hemoglobin levels. Patients should be screened for MRSA, especially in countries with known high MRSA infection rates, e.g., South and North America, Asia and Malta [22], as MRSA positivity has been evident in $80 \%$ of all post-operatively developed fistulae [23]. The same study demonstrated previous radiation and MRSA positivity to be the only predictors for the development of fistula [23]. The incidence of wound infection has been reported to be as high as $87 \%$. Short regimen antibiotic prophylaxis covering aerobic and anaerobic bacteria has been shown to reduce the risk of infection in clean-contaminated major oncological head and neck surgery, and is also advisable in clean major oncological head and neck surgery [24]. Smoking and alcohol consumption should be discouraged to reduce the respiratory and metabolic problems associated with these agents.

The development of PCF is a frequent and feared complication of salvage surgery, especially salvage laryngectomies with concomitantly performed neck dissections [25]. The rate of development of PCF appears to correlate with the time from primary treatment to salvage surgery, with a mean time of 19.5 months in those who developed a PCF versus 47 months in those who did not $(p=0.02)$ [26]. In a 
meta-analysis of 33 studies performed by Sayles and Grant [27], the incidence of PCF was $14.3 \%$ in primary laryngectomy, $27.6 \%$ in salvage laryngectomy and $10.3 \%$ in salvage laryngectomy with flap reconstruction. Reconstruction with either free or pedicled flaps allows restoration of function and provides aid in wound healing by introducing non-irradiated tissue. A meta-analysis performed by Paleri et al. [28] indicated that the use of vascularized tissue from outside the radiation field significantly reduces the rate of PCF formation. The application of a myofascial pectoralis major flap in salvage laryngectomies to enhance the pharyngeal anastomosis has been shown to reduce fistula rates from 50 to $25 \%$. If applicable, flaps should be considered early in the surgical salvage setting [29].

The use of chemotherapy is associated with an incidence of fistula formation of $34.1 \%$ compared with $22.8 \%$ in patients treated with RT alone [26].

General measures to minimize complications include prevention of deep venous thrombosis prophylaxis and use of anti-emetics to minimize tension to the wound by reducing nausea and vomiting, in addition to stabilization of hemoglobin, blood sugar and electrolyte balance.

\section{Surgical salvage approaches}

Salvage surgery especially salvage laryngectomy is associated with high morbidity rates, poor overall and diseasespecific survival, prolonged hospital stays and decreased quality of life compared with primary surgery [13, 30, 31]. With respect to survival rates, salvage surgery has been shown to be most effective for recurrent laryngeal cancer and least effective in pharyngeal tumors [32]. Some authors suggest less radical approaches, whereas others promote extensive resection with reconstruction. The question of whether neck dissection is indicated for patients with recurrent primary tumors without evidence of current or previous neck disease remains open, although there is evidence that neck dissection may be beneficial for patients with more advanced RT stages [33].

As an alternative to total laryngectomy, open partial laryngectomies, particularly the supracricoid procedures, may be reliable salvage operations, if suitably indicated [34]. While preserving function, partial laryngectomy affords no survival advantage. In a retrospective analysis of 56 patients with recurrent laryngeal cancer comparing total to partial laryngectomies, patient survival was not affected by the primary treatment or by salvage surgical approach, but was improved by obtaining negative margins [35]. Patients with an early disease relapse appear to have a worse prognosis compared with patients with a delayed relapse [36].

In general, open approaches are associated with a high incidence of major complications and often produce defects that require microvascular reconstruction, particularly in a radiated field. Recently, transoral approaches using laser or robotic systems have shown great promise in the surgical resection of recurrent early stage HNSCC. In a retrospective analysis, White et al. [37] showed the feasibility of transoral robotic surgery (TORS) in a salvage setting for recurrent oropharyngeal tumors with a significantly lower incidence of tracheostomy and feeding tube use, shorter overall hospital stays, decreased operative time, less blood loss, significantly decreased incidence of positive margins and no post-operative fistula compared with open procedures [37]. The two-year recurrence-free survival rate was significantly higher in the TORS group than in the open approach group (74 and $43 \%$, respectively) $(p<0.01)$. Transoral laser microsurgery (TLM) for recurrent T1-T3 supraglottic tumors was shown to be feasible, with twoand five-year overall survival rates of 85.7 and $68.6 \%$, respectively [38]. In another study including 91 patients with recurrent T1-T4 pharyngeal and laryngeal cancer following prior treatment, three-year local control, survival and disease-specific survival were 70,62 and $64 \%$, respectively [39]. For recurrent early glottic tumors, treated with salvage TLM, five-year overall survival, disease-specific survival, local control and locoregional control rates have been shown to be $89.9,97.9,62.3$ and $60.1 \%$, respectively $(n=50)$. The larynx preservation rate at long-term followup was $86 \%$ [40].

Obviously, there is a selection bias when results for tumors suitable for transoral procedures are compared with those that are not. Nevertheless, these data suggest that transoral approaches, when feasible, should be preferred over open approaches as complications, particularly formation of fistula, are significantly reduced with acceptable oncological safety.

In an effort to achieve greater local and regional control in recurrent HNSCC, re-irradiation alone or in combination with chemotherapy can be considered following salvage surgery. A phase III multi-center study of recurrent HNSCC in previously irradiated post-salvage surgery randomized patients to post-operative observation or reirradiation with concurrent chemotherapy groups. Local disease control and disease-free survival were improved in the patients who received re-irradiation and chemotherapy [41], although there was no significant difference in overall survival compared with those observed after salvage surgery alone. Grade 3 and 4 toxicity was as high as $40 \%$ compared with $10 \%$ in those randomized to post-operative observation.

Palliative chemotherapy is considered the standard of care for patients with unresectable tumors. Multi-agent chemotherapy regimens may have a response rate of up to $35 \%$, but results are rarely durable and long-term survival is rare [42]. In these patients, re-irradiation, if applicable, 
is the only potentially curative treatment modality. With novel technologies to improve external beam irradiation employing new concepts on dose, fractionation, intensitymodulated radiation therapy and stereotactic approach, as well as brachytherapy, increased response with reduced toxicity is the aim. The $\mathrm{RTOG}^{\circledR}$ has completed two phase-II studies using re-irradiation and chemotherapy in this patient population. RTOG $^{\circledR}{ }_{-}-96-10$ used concurrent hydroxyurea and 5-flourouracil achieving a median survival of 8.5 months and a two-year survival rate of $15.2 \%$ [43]. RTOG ${ }^{\circledR}-99-11$ employed concurrent cisplatin and paclitaxel and achieved a median survival of 12.1 months and a two-year survival rate of $25.9 \%$ [44]. However, acute toxicity was high in both studies with almost $50 \%$ of patients suffering grade 3 toxicity and $23 \%$ grade 4 in RTOG $^{\circledR}-99-11$.

\section{Palliative salvage surgery}

Salvage surgery in a palliative setting can be offered and performed to reduce pain and bleeding, or relieve airway and/or esophageal obstruction. However, these procedures are associated with high complication rates. The potential benefits in relation to associated risks for the patients have to be carefully evaluated.

Rehabilitative salvage surgery directed to improve functionality, particularly voice and swallowing, after definitive treatment without evidence of recurrent disease, has been increasingly discussed. Frequent aspiration and frustrating voice rehabilitation can lead the patient to request rehabilitative surgery. The decision to offer such a procedure needs to be carefully evaluated and should be only performed in agreement with the patient when conservative treatment has shown no improvement.

\section{Conclusion}

Salvage surgery in patients with recurrent HNSCC following $\mathrm{pR}(\mathrm{C}) \mathrm{T}$ remains a controversial topic and many aspects in this regard lack sufficient evidence as to their benefit. Only a few patients with recurrent disease are good candidates for salvage surgery, as many suffer from co-morbidities related to their previous HNSCC treatment. Therefore, preoperative consultation, patient evaluation and patient education are essential.

Complications of salvage surgery are often multifactorial and interrelated. The indications for and against salvage surgery need to be carefully considered and met by an experienced, interdisciplinary head and neck oncology group, preferably at a tertiary care center. Preoperative evaluation and correction of nutritional deficiencies and co-morbidities are critical to good outcomes and to minimize complications.

Transoral approaches such as TORS and TLM, which seem to be associated with a reduced complication rate in a salvage setting, can be an alternative to open approaches for selected tumors. Currently, there are only few data on comparing transoral to open surgery. Long-term results, preferably from multi-center studies, should eventually reveal oncological safety, survival rates and functional outcome of these approaches.

Because of advances in extirpative and reconstructive surgical techniques, as well as progress in non-surgical modalities, the treatment of recurrent HNSCC has shifted within the last decades from palliation toward curative therapy employing surgery, $\mathrm{R}(\mathrm{C}) \mathrm{T}$ or a combination of both with improved survival rates, but which are still less than fully satisfactory.

\section{References}

1. Parkin DM, Bray F, Ferlay J, Pisani P (2005) Global cancer statistics, 2002. CA Cancer J Clin 55:74-108

2. Fremgen AM, Bland KI, McGinnis LS Jr, Eyre HJ, McDonad CJ, Menck HR, Murphy GP (1999) Clinical highlights from the National Cancer Data Base, 1999. CA Cancer J Clin 49:145-158

3. Goodwin WJ Jr (2000) Salvage surgery for patients with recurrent squamous cell carcinoma of the upper aerodigestive tract: when do the ends justify the means? Laryngoscope 110 (Suppl 93): $1-18$

4. Strojan P, Corry J, Eisbruch A, Vermorken JB, Mendenhall WM, Lee AWM, Haigentz M Jr, Beitler JJ, de Bree R, Takes RP, Paleri V, Kelly CG, Genden EM, Bradford CR, Harrison LB, Rinaldo A, Ferlito A (2014) Recurrent and second primary squamous cell carcinoma of the head and neck: when and how to re-irradiate. Head Neck [Epub ahead of print]

5. Brockstein B, Haraf DJ, Rademaker AW, Kies MS, Stenson KM, Rosen F, Mittal BB, Pelzer H, Fung BB, Witt ME, Wenig B, Portugal L, Weichselbaum RW, Vokes EE (2004) Patterns of failure, prognostic factors and survival in locoregionally advanced head and neck cancer treated with concomitant chemoradiotherapy: a 9-year, 337-patient, multi-institutional experience. Ann Oncol 15:1179-1186

6. Bachar GY, Goh C, Goldstein DP, O’Sullivan B, Irish JC (2010) Long-term outcome analysis after surgical salvage for recurrent tonsil carcinoma following radical radiotherapy. Eur Arch Otorhinolaryngol 267:295-301

7. Zafereo ME, Hanasono MM, Rosenthal DI, Sturgis EM, Lewin JS, Roberts DB, Weber RS (2009) The role of salvage surgery in patients with recurrent squamous cell carcinoma of the oropharynx. Cancer 115:5723-5733

8. Agra IM, Carvalho AL, Ulbrich FS, de Campos OD, Martins EP, Magrin J, Kowalski LP (2006) Prognostic factors in salvage surgery for recurrent oral and oropharyngeal cancer. Head Neck 28:107-113

9. Röösli C, Studer G, Stoeckli SJ (2010) Salvage treatment for recurrent oropharyngeal squamous cell carcinoma. Head Neck 32:989-996

10. Sanabria A, Kowalski LP, Shaha AR, Silver CE, Werner JA, Mandapathil M, Takes RP, Strojan P, Rinaldo A, Ferlito A (2014) Salvage surgery for head and neck cancer: a plea for better 
definitions. Eur Arch Otorhinolaryngol (Editorial) [Epub ahead of print]

11. Ganly I, Patel S, Matsuo J, Singh B, Kraus D, Boyle J, Wong R, Lee N, Pfister DG, Shaha A, Shah J (2005) Postoperative complications of salvage total laryngectomy. Cancer 103:2073-2081

12. Pang L, Jeannon JP, Simo R (2011) Minimizing complications in salvage head and neck oncological surgery following radiotherapy and chemo-radiotherapy. Curr Opin Otolaryngol Head Neck Surg 19:125-131

13. Sewnaik A, Keereweer S, Al-Mamgani A, de Baatenburg Jong RJ, Wieringa MH, Meeuwis CA, Kerrebijn JD (2012) High complication risk of salvage surgery after chemoradiation failures. Acta Otolaryngol 132:96-100

14. Agra IM, Carvalho AL, Pontes E, Campos OD, Ulbrich FS, Magrin J, Kowalski LP (2003) Postoperative complications after en bloc salvage surgery for head and neck cancer. Arch Otolaryngol Head Neck Surg 129:1317-1321

15. Tønnesen H, Nielsen PR, Lauritzen JB, Møller AM (2009) Smoking and alcohol intervention before surgery: evidence for best practice. Br J Anaesth 102:297-306

16. Paydarfar JA, Birkmeyer NJ (2006) Complications in head and neck surgery: a meta-analysis of postlaryngectomy pharyngocutaneous fistula. Arch Otolaryngol Head Neck Surg 132:67-72

17. Lang S, Wollenberg B, Dellian M, Steuer-Vogt MK, Schwenzer K, Sautier W, Chucholowski M, Eckel R, Faas I, Wilmes E, Ehrenfeld M, Arnold W, Kastenbauer E, Hölzel D (2002) Clinical and epidemiological data of patients with malignomas of the head and neck. Laryngorhinootologie 81:499-508 (Article in German)

18. de Bree R, Deurloo EE, Snow GB, Leemans CR (2000) Screening for distant metastases in patients with head and neck cancer. Laryngoscope 110:397-401

19. Ng SH, Chan SC, Liao CT, Chang JT, Ko SF, Wang HM, Chin SC, Lin CY, Huang SF, Yen TC (2008) Distant metastases and synchronous second primary tumors in patients with newly diagnosed oropharyngeal and hypopharyngeal carcinomas: evaluation of (18)F-FDG PET and extended-field multi-detector row CT. Neuroradiology 50:969-979

20. Senft A, de Bree R, Hoekstra OS, Kuik DJ, Golding RP, Oyen WJ, Pruim J, van den Hoogen FJ, Roodenburg JL, Leemans CR (2008) Screening for distant metastases in head and neck cancer patients by chest CT or whole body FDG-PET: a prospective multicenter trial. Radiother Oncol 87:221-229

21. Xu G, Li J, Zuo X, Li C (2012) Comparison of whole body positron emission tomography (PET)/PET-computed tomography and conventional anatomic imaging for detecting distant malignancies in patients with head and neck cancer: a meta-analysis. Laryngoscope 122:1974-8

22. Stefani S, Chung DR, Lindsay JA, Friedrich AW, Kearns AM, Westh H, Mackenzie FM (2012) Meticillin-resistant Staphylococcus aureus (MRSA): global epidemiology and harmonisation of typing methods. Int J Antimicrob Agents 39:273-282

23. Jeannon JP, Orabi A, Manganaris A, Simo R (2010) Methicillin resistant Staphylococcus aureus infection as a causative agent of fistula formation following total laryngectomy for advanced head and neck cancer. Head Neck Oncol 2:14

24. Simo R, French G (2006) The use of prophylactic antibiotics in head and neck oncological surgery. Curr Opin Otolaryngol Head Neck Surg 14:55-61

25. Khan NA, Medina JE, Sanclement JA, Krempl GA (2013) Fistula rates after salvage laryngectomy: comparing pectoralis myofascial and myocutaneous flaps. Laryngoscope [Epub ahead of print]

26. Scotton WJ, Nixon IJ, Pezier TF, Cobb R, Joshi A, Urbano TG, Oakley R, Jeannon JP, Simo RS (2013) Time interval between primary radiotherapy and salvage laryngectomy: a predictor of pharyngocutaneous fistula formation. Eur Arch Otorhinolaryngol [Epub ahead of print]
27. Sayles M, Grant DG (2013) Preventing pharyngo-cutaneous fistula in total laryngectomy: a systematic review and meta-analysis. Laryngoscope [Epub ahead of print]

28. Paleri V, Drinnan M, van den Brekel MW, Hinni ML, Bradley PJ, Wolf GT, de Bree R, Fagan JJ, Hamoir M, Strojan P, Rodrigo JP, Olsen KD, Pellitteri PK, Shaha AR, Genden EM, Silver CE, Suárez C, Takes RP, Rinaldo A, Ferlito A (2014) Vascularized tissue to reduce fistula following salvage total laryngectomy: a systematic review. Laryngoscope [Epub ahead of print]

29. Sayles M, Koonce SL, Harrison L, Beasley N, McRae AR, Grant DG (2013) Pharyngo-cutaneous fistula complicating laryngectomy in the chemo-radiotherapy organ-preservation epoch. Eur Arch Otorhinolaryngol [Epub ahead of print]

30. Poole ME, Sailer SL, Rosenman JG, Tepper JE, Weissler MC, Shockley WW, Yarbrough WG, Pillsbury HC 3rd, Schell MJ, Bernard SA (2011) Chemoradiation for locally advanced squamous cell carcinoma of the head and neck for organ preservation and palliation. Arch Otolaryngol Head Neck Surg 127:1446-1450

31. Aarts MC, Rovers MM, Grau C, Grolman W, van der Heijden GJ (2011) Salvage laryngectomy after primary radiotherapy: what are prognostic factors for the development of pharyngocutaneous fistulae? Otolaryngol Head Neck Surg 144:5-9

32. Arnold DJ, Goodwin WJ, Weed DT, Civantos FJ (2004) Treatment of recurrent and advanced stage squamous cell carcinoma of the head and neck. Semin Radiat Oncol 14:190-195

33. Sanabria A, Silver CE, Olsen KD, Medina JE, Hamoir M, Paleri V, Mondin V, Rinaldo A, Rodrigo JP, Suárez C, Bödeker CC, Hinni ML, Kowalski LP, Teymoortash A, Werner JA, Takes RP, Ferlito A (2014) Is elective neck dissection indicated during salvage surgery in head and neck squamous cell carcinoma? Eur Arch Otorhinolaryngol [Epub ahead of print]

34. de Vincentiis M, De Virgilio A, Bussu F, Gallus R, Gallo A, Bastanza G, Parrilla C, Greco A, Galli J, Turchetta R, Almadori G, Pagliuca G, Valentini V, Paludetti G (2013) Oncological results of the surgical salvage of recurrent laryngeal SCC in a multicentric retrospective series. The emerging role of supracricoid partial laryngectomy. Head Neck [Epub ahead of print]

35. Li M, Lorenz RR, Khan MJ, Burkey BB, Adelstein DJ, Greskovich JF Jr, Koyfman SA, Scharpf J (2013) Salvage laryngectomy in patients with recurrent laryngeal cancer in the setting of nonoperative treatment failure. Otolaryngol Head Neck Surg 149:245-251

36. Begg AC (2012) Predicting recurrence after radiotherapy in head and neck cancer. Semin Radiat Oncol 22:108-118

37. White H, Ford S, Bush B, Holsinger FC, Moore E, Ghanem T, Carroll W, Rosenthal E, Sweeny L, Magnuson JS (2013) Salvage surgery for recurrent cancers of the oropharynx: comparing TORS with standard open surgical approaches. JAMA Otolaryngol Head Neck Surg 139:773-778

38. Hong JC, Kim SW, Lee HS, Han YJ, Park HS, Lee KD (2013) Salvage transoral laser supraglottic laryngectomy after radiation failure: a report of seven cases. Ann Otol Rhinol Laryngol 122:85-90

39. Grant DG, Salassa JR, Hinni ML, Pearson BW, Hayden RE, Perry WC (2008) Transoral laser microsurgery for recurrent laryngeal and pharyngeal cancer. Otolaryngol Head Neck Surg 138:606-613

40. Huang J, Yu Z, Fang J, Chen X, Chen X, Huang Z (2013) Salvage transoral laser microsurgery for early recurrent glottic carcinoma after primary laser treatment. Acta Otolaryngol 133:531-537

41. Janot F, de Raucourt D, Benhamou E, Ferron C, Dolivet G, Bensadoun RJ, Hamoir M, Géry B, Julieron M, Castaing M, Bardet E, Grégoire V, Bourhis J (2008) Randomized trial of postoperative reirradiation combined with chemotherapy after salvage surgery compared with salvage surgery alone in head and neck carcinoma. J Clin Oncol 26:5518-5523 
42. Forastiere AA, Leong T, Rowinsky E, Murphy BA, Vlock DR, DeConti RC, Adams GL (2001) Phase III comparison of highdose paclitaxel + cisplatin + granulocyte colony-stimulating factor versus low-dose paclitaxel + cisplatin in advanced head and neck cancer: eastern cooperative oncology group study E1393. J Clin Oncol 19:1088-1095

43. Spencer SA, Harris J, Wheeler RH, Machtay M, Schultz C, Spanos W, Rotman M, Meredith R, Ang KK (2008) Final report of RTOG 9610, a multi-institutional trial of reirradiation and chemotherapy for unresectable recurrent squamous cell carcinoma of the head and neck. Head Neck 30:281-288

44. Langer CJ, Harris J, Horwitz EM, Nicolaou N, Kies M, Curran W, Wong S, Ang K (2007) Phase II study of low-dose paclitaxel and cisplatin in combination with split-course concomitant twicedaily reirradiation in recurrent squamous cell carcinoma of the head and neck: results of radiation therapy oncology group protocol 9911. J Clin Oncol 25:4800-4805 